\title{
Youth motivations to watch sports in Indian context: exploring cross- nationality and cross-gender differences
}

\author{
Anish YOUSAF \\ Lovely Professional University Phagwara (Punjab), India \\ Makhmoor BASHIR \\ Lovely Professional University Phagwara (Punjab), India \\ Insha AMIN \\ Baba Ghulam Shah Badshah University Rajouri (J\&K), India
}

\begin{abstract}
The current study revolves around research in sport consumption motivations exploring Nationality and Gender difference across fan motivations to watch sports in a way similar to Kwon and Trail (2001) in Indian context, a subject neglected until now. Data was collected from 260 respondents from India's largest Private University. Findings reveal Group Affiliation as the most important motivation followed by Eustress (entertainment), Aesthetics, and Self-Esteem. Betting on sports was found as the least preferred motivation. Findings revealed Nationality having a significant impact on Group Affiliation and Aesthetics while Gender has a significant impact on Group Affiliation, Eustress as well as on level of identification with sport. These findings have implications for sports marketers of different sporting events involved in marketing of sports related activities to enhance their marketing practices. The results of the current study are of interest for physical education departments of large private Universities which can use them to promote their sports events at a large scale. The last section of the study discusses the results in detail followed by directions for future research.
\end{abstract}

Keywords: aesthetics, eustress, fans, group affiliation, spectator, sport consumption, sport motivation, self-esteem, sports marketing

Please cite the article as follows: Yousaf, A., Bashir, M. and Amin, I. (2015), "Youth motivations to watch sports in Indian context: exploring cross-nationality and cross-gender differences", Management \& Marketing. Challenges for the Knowledge Society, Vol. 10, No. 4, pp. 330-340, DOI: 10.1515/mmcks-2015-0022.

\section{Introduction}

Sports marketing is flourishing at a very fast pace and has emerged as a multi-billion dollar industry gathering huge momentum throughout global markets, BRIC nations being no exemption. Sports like Football and Cricket are considered unofficial religion in few BRIC nations. It is forecasted by Price Water House Coopers (2011) that sports industry is expected to increase by the coming decade in BRIC nations with Indian market estimated at $\$ 2$ billion annually by 2015 growing at a rate of $5.0 \%$ following Brazil which has the highest CAGR of 5.3\%. Other sport events like tennis, Formula 1

Correspondence: Yousaf Anish anishyousaf86@ gmail.com 
racing and hockey are also catching up with the number of followers (fans). Statistics show that sports market in BRIC countries is an incredibly unique sector and is one of the most profitable businesses.

Sports hold a very important place in the life of a dedicated fan permanently connected to different sport events / activities (Naik and Gupta, 2012). Fans from different geographical borders, irrespective of gender, religion, and nationality, watch or attend these events and have different reasons or drives for that matter. Exploring fan motivations for watching sport has become a popular area of research among sport psychologists to explain drives that motivate individuals to take an active part in such events (Hsieh et al., 2011; Kwon and Trail, 2001). Measurement and understanding of such motivations of fans also play a crucial role for sport (event) marketers. Previous researchers have investigated fan motivations to watch sport by exploring cultural and gender differences in different contexts across different sports (Hsieh et al. 2011; Wann et al., 2008; Won and Kitamura, 2007, Armstrong and Stratta, 2004; Kwon and Trail, 2001).

Recently et al. (2011) and Menefee (2009) studied cultural differences across professional baseball consumption behavior comparing the United States (US) and other different cultures, Taiwan (baseball) and China (basketball), respectively. Both researchers reported differences across selected dimensions of sport consumption motivations between the US and other cultures. Comparing individualism and collectivism, Reim (2013) found that spectators from various nations differ significantly when attending sporting events. Socialization seeking is the most important motive in collectivist cultures compared to individualist nations. Kwon and Trail (2001) explored sport motivation differences across American and Non-American intercollegiate students for attending inter-collegiate sports using a market segmentation approach and advocated for similar studies in different contexts.

In India, sports marketing industry is growing at a fast pace. Over the last5 years, many sport leagues have grown and have established themselves on global platform. Indian Premier League (IPL), Indian Hockey League (IHL), Indian Super League (ISL), Pro Kabaddi League (PKL), Indian Badminton League (IBL) etc. are few examples. These events also compete against each other for attracting and retaining potential sports fans. Previous researches have focused on exploring sport consumption motivations of fans. Indian context has been highly neglected despite the growth in Indian sports market and lack of literature on Indian sports market context explaining fan motivations to watch these sport events. Current study aims to fulfill this gap in literature. The objective of the study revolves around research in sport consumer motivations across Youth by replicating the study of Kwon and Trail (2001) in Indian context. The value of the current study is to illustrate the underlying differences in sport consumption behaviors among youth. For having a better understanding of the Gender differences across Indian and Non-Indian youth, data was analyzed at two levels, first for the combined sample and then for the individual sample of nationalities exploring interesting findings which can be used by sport marketers or marketers of sporting events in large international Universities who can customize their marketing strategies while targeting two different fan groups. However, the scope of the study is limited to the youth of a large private university in India and the findings can be useful to the marketers for providing insight to private universities for a strategic approach. 


\section{MMCKS Review of the literature}

Sports act as a major source of entertainment for people across global boundaries. Burke (2002) defined sports as highly organized games and competitions requiring physical skills, strategy and chance as well as physical prowess. Sports do not recognize any barrier, be it religious, racial, educational, geographical or ethnic and plays a dominant role as a form of symbolic dialogue to develop the people as well as the civilization.

The psychological link prevailing amongst people and sports has made sporting leagues as well as sports teams extremely popular. Huge amounts of time, cash and resources are spent to attend events like: Olympics, FIFA, ICC, Wimbledon, Formula 1, NBA, and Indian Premier League. These proceedings touch the feelings of fans and have become a significant part of their life. Nowadays sports and respective teams compete not only with each other but also with other businesses and other leisure offerings making it compulsory for sport managers to develop and manage fertile relations with their fans and other stakeholders (Bauer et al., 2005). Commercialization and professionalization of team sports have produced an increased competition within sports market (Rosca, 2011). This in turn has led to every sport manager taking interest in understanding the importance of 'team fans' to win long-term fan loyalty that ensures their involvement in the team's activities leading to the economic success of teams.

Wann (1995) defines a fan as one who is enthusiastic about a particular sport or athlete. Agas et al. (2012) elucidates that 'fan', the shortened form of the word 'fanatic', expresses enthusiasm, passion and eagerness and even "moving beyond reason". Dobel (2010) highlights the term 'Home Field advantage' which has a huge impact on the sports nowadays. Passionate sports fans are able to uplift athletes and players by transferring their emotional support to players through cheering.

Fans watch sports for a wide variety of reasons. For long time researchers tried to investigate the factors that motivate individuals to attend sport events. Sloan et al. in 1987 offered a sport consumer motivation measure - Sports Need for Achievement and Power Scale (SNAPS). Sloan (1989) later presented an analysis of the SNAPS deriving 5 motivations: Salubrious Effects, Stress (release) and Stimulation Seeking, Aggression and Catharsis, Entertainment, and Achievement.

On the other hand, Wann (1995) presented the Sports Fan Motivation Scale and identified 8 motivation factors: eustress [drama], self-esteem, escape [from ordinary life], entertainment, economic [gambling] factors, aesthetics, group affiliation [socialization] and family needs. Some other researchers like Milne and McDonald (1999) suggested 12 marginally dissimilar sport fan motivation factors: risk taking, stress release, aggression, affiliation, skill mastery, aesthetics, self-esteem, selfactualization, value development, social facilitation, vicarious achievement and competition. However when we talk about the acceptability of these scales some scholars like Trail and James (2001) claim that these scales where methodologically inadequate with respect to their construct reliability and validity.

Trail and James (2001) developed their own motivation scale called motivation scale for sport consumption which consists of nine motivation constructs. The researchers applied rigorous statistical tests for their validity and reliability. The nine constructs are: knowledge [acquiring], aesthetics, drama, escape, family, physical attraction, physical skills [players], social interaction [group affiliation] and achievement [vicarious]. In a number of recent studies, spectator motivations to attend sporting events have been analyzed across 13 different sports: Wann et al. (2008) - mixed martial arts; Kim et al. (2008) - men's football and basketball, women's basketball; 
Robinson and Trail (2005) - men's baseball and wrestling, women's softball. Some studies disclose that motives might vary by nationality, sport and emotional attachment (Koo and Hardin, 2008; Wann et al., 2008; Won and Kitamura, 2007).

The motivation to watch sports might differ across numerous diverse cultures and contexts (Hsieh et al., 2011; Kwon and Trail, 2001; Won and Kitamura, 2007). Many scholars have studied race and cultural motivation which affect spectator behavior. Won and Kitamura (2007) while studying the Japan League and Korean League found that three factors: drama, vicarious achievement and entertainment contributed to the motivation of spectators. The Japanese were more likely to attend with family members or alone whereas Koreans were more romantic and would attend with boyfriend/girlfriend. Studying Portuguese spectator behavior, Correia and Estevez (2007) found that various cultures and ethnic backgrounds can influence motivation factors among international spectators. Armstrong and Stratta (2004) came to the conclusion that Afro-American spectators were more influenced than Caucasian spectators on seven motivations particularly entertainment, social atmosphere, and special promotions.

Kwon and Trail (2001) explore nationality and gender differences between American and Non-American students when watching sports and their level of identification with this activity. They found that both gender and nationality impact the frequency of watching sport as well as their motivation and call for replication of the study. Following the footsteps of Kwon and Trail (2001), this study attempts to explore nationality and gender differences across sport watching motives and their level of identification with sports.

\section{Research methodology \\ Procedure and Participants}

The sample of this study consists of students enrolled in a large Private Indian University (Lovely Professional University, Punjab). The sample was divided into two strata (Indian and Non-Indian students). The final sample was selected using systematic random sampling from each stratum. Stratified sampling technique was used for data collection from the respondents. Data was collected from 260 sport fans intercepted at different locations within the University. After omitting outliers and half-filled forms, 216 were kept for further analysis.

The sample characteristics were $67 \%$ males, 33\% females (Indians $=52 \%$, and Non-Indians $=48 \%$ ) in the age range $17-24$ years. $65 \%$ had a high school degree followed by $35 \%$ with a University degree. Also, $50 \%$ of the respondents were having monthly household income above Rs 50,000, 35\% were having monthly household income in between Rs 25000-50000 and 15\% were having monthly household income in the range of Rs 10000-25000. Football was the most Liked / played sport by the respondents (40\%), followed by Cricket (32\%), Basketball (12\%), Athletics (10\%) and others $(6 \%)$.

\section{Instrumentation}

Before collecting the final data from respondents, a pre-qualitative study was conducted with a focus group of twelve students, from management and physical education department of the university, to confirm the measures. The main purpose of the prequalitative study was to confirm the measures and the wording of the measures used in 
the questionnaire. Once the measures were confirmed and the wording of the measures was made suitable to the target group, researchers reached the final quantitative study involving questionnaire. The questionnaire contained three relevant sections: the demographic information of the respondents, the Sport Fan Motivation Scale (Wann, 1995), and an identification scale for sports (total of 17 items).

\section{Demographics}

This was the first section of the survey incorporating questions about the demographic and psychographic characteristics of the participants. Questions related to participant's gender, age, nationality, monthly household income were asked.

\section{Measurement}

Sport Fan Motivation Scale - In order to measure the motivation of watching sports, five fan motive subscales were selected from Wann (1995) in a way similar to Kwon and Trail (2001). These five subscales were: eustress, Group Affiliation, Entertainment, betting on sport (economics), self-esteem and Aesthetics measured on a 9 point-Likert scale from 1 (strongly disagree) to 9 (strongly agree). Kwon and Trail (2001) gives satisfactory reasons for omitting three subscales of Wann (1995) for measuring sport watching motives. They argued that students do not have family with them in University so family subscale can be skipped whereas the other two subscales i.e. entertainment subscale and escape subscale had a very high correlation with eustress subscale (Wann, 1995).

Identification scale - Identification of respondents for sport was measured using Trail and James (2001) on a 9 point-Likert scale from 1 (strongly disagree) to 9 (strongly agree) similar to SFMS.

\section{Data analysis and findings}

\section{Reliability Analysis}

Fan Motives. Cronbach's alpha coefficient was calculated for each variable to assess the reliability of the instrument (Table 1$)$ : aesthetics $(\alpha=0.76)$, self-esteem $(\alpha=0.79)$, eustress $(\alpha=0.85)$, betting on sport $(\alpha=0.82)$, and group affiliation $(\alpha=0.74)$ which were above the accepted value of $\alpha=0.70$ (Nunnally, 1978). When explored about the main motivation of youths for watching sports (Table 2), it was found that group affiliation $(\mathrm{M}=7.67$, $\mathrm{S} . \mathrm{D}=0.73)$ was the primary motivation followed by eustress $(\mathrm{M}=$ 7.24, S.D = 1.85), aesthetics $(M=7.20, S . D=1.82)$, self-esteem $(M=6.66, S . D=1.89)$. Data analysis revealed that economic (betting on sport) was the least preferred motivation ( $M=3.98$, S.D = 2.01) which was found similar to Kwon and Trail (2001).

\begin{tabular}{|lc|}
\hline Table 1: Cronbach alpha for motive subscales and identification scale \\
\hline MEASURE \& VARIABLE & ALPHA \\
\hline Aesthetics & $\mathbf{0 . 7 6}$ \\
1.I like watching sports for the creative values \\
2.I enjoy the competition in the sport \\
3.I enjoy watching sports because to me sports are a form of art \\
Eustress \\
1. I get excited when I am watching my favorite sport team in a sport
\end{tabular}


2. I feel excited when I watch sport

3. I enjoy the competitive rivalry in sport

Group Affiliation

0.74

1. I use sports as a topic when I meet new people

2. I enjoy watching sports more when I am with a large group of people

3. Most of my friends are sports fan and that is one of the reasons that I like sports

Economic (Betting On Sport)

0.82

1. I like sports because I can bet on the sporting event

2. For me making money by betting on sporting event is an enjoyable part of being a fan

Self-Esteem (Vicarious Achievement)

0.79

1. I feel a personnel sense of achievement when my favorite team wins in the sporting event

2. I feel like I have won when my favorite team wins in the sport

3. To me my favorite team success is my success and their losses are my losses

Identification With Sport

0.91

1. I would support my favorite sport team even if there was no star player on the team

2. I would support my favorite sport team even if they lost all the game in a season

3. I would support my favorite sport team regardless of whether they lost or win

Source: Authors' own research

Identification with sport. Identification of fans with sports, in general, was measured by 3 items. The Cronbach's alpha value for fan identification was 0.91 which was very good (Table 1 ).

\begin{tabular}{|c|c|c|c|c|c|}
\hline \multicolumn{6}{|c|}{$\begin{array}{l}\text { Table 2: Mean (standard deviation) of motives (by group and gender) \& } \\
\text { identification }\end{array}$} \\
\hline \multirow[b]{2}{*}{ MOTIVES } & \multirow[b]{2}{*}{$\begin{array}{l}\text { COMBINED } \\
\text { SAMPLE }\end{array}$} & \multicolumn{2}{|c|}{ NATIONALITY } & \multicolumn{2}{|l|}{ GENDER } \\
\hline & & INDIANS & $\begin{array}{l}\text { NON- } \\
\text { INDIANS }\end{array}$ & MALE & FEMALE \\
\hline $\begin{array}{l}\text { Group } \\
\text { Affiliation }\end{array}$ & $7.67(0.73)$ & $\begin{array}{l}7.68^{\mathrm{a}} \\
(0.59)\end{array}$ & $\begin{array}{l}7.67 a \\
(0.66) \\
\end{array}$ & $\begin{array}{l}7.74 \mathrm{~b} \\
(0.65)\end{array}$ & $7.12^{\mathrm{b}}(0.57)$ \\
\hline Eustress & $7.24(1.85)$ & $\begin{array}{l}7.04 \\
(1.92)\end{array}$ & $\begin{array}{l}7.43 \\
(1.57)\end{array}$ & $\begin{array}{l}7.30^{\mathrm{b}} \\
(1.85)\end{array}$ & $7.10^{\mathrm{b}}(1.74)$ \\
\hline Aesthetics & $7.20(1.82)$ & $\begin{array}{l}7.02^{\mathrm{a}} \\
(1.94)\end{array}$ & $\begin{array}{l}7.38^{\mathrm{a}} \\
(1.70)\end{array}$ & $\begin{array}{l}7.31^{\mathrm{b}} \\
(1.84)\end{array}$ & $7.00^{\mathrm{b}}(1.77)$ \\
\hline $\begin{array}{l}\text { Self-Esteem } \\
\text { (Vicarious } \\
\text { Achievement) }\end{array}$ & 6.66 (1.89) & $\begin{array}{l}6.41 \\
(1.87)\end{array}$ & $\begin{array}{l}6.89 \\
(1.96)\end{array}$ & $6.77(1.66)$ & $6.43(2.07)$ \\
\hline $\begin{array}{l}\text { Economic } \\
\text { (Betting On } \\
\text { Sport }\end{array}$ & $3.98(2.01)$ & $\begin{array}{l}3.77 \\
(2.46)\end{array}$ & $\begin{array}{l}4.18 \\
(2.18)\end{array}$ & $4.24(2.30)$ & $3.45(2.20)$ \\
\hline $\begin{array}{l}\text { Identification } \\
\text { With Sport }\end{array}$ & $6.92(1.05)$ & $\begin{array}{l}7.06 \\
(2.09)\end{array}$ & $\begin{array}{l}6.78 \\
(1.50)\end{array}$ & $\begin{array}{l}7.01^{b} \\
(1.76)\end{array}$ & $6.73^{b}(1.28)$ \\
\hline \multicolumn{6}{|c|}{$\begin{array}{l}\text { Note: }{ }^{a} \text { Mean differences between Indian \& non-Indian Students significant at } P< \\
0.05 \text {. } \\
\text { bMean differences between genders significant at } P<0.05 \text {. }\end{array}$} \\
\hline
\end{tabular}

Source: Authors' own research

\section{Subgroup Differences}

Descriptive statistics were calculated, and compared, to explore subgroup differences across groups in terms of their motivations to watch sports (Table 2). Independent 
sample t-test was used to explore the statistically significant differences between different motivations (and identification with sport) means of taking gender and nationality of respondents as the grouping variables.

Nationality differences. Data analysis indicated that two groups (Indians and nonIndians) differed in context of two motives out of the five motive subscales (Table 2) . These motives were aesthetics and group affiliation. For aesthetic motive, Non-Indian students scored significantly higher than Indian students $(M=7.38, M=7.02)$ whereas for group affiliation, the mean difference is lower, Indian students scored significantly higher than Non-Indians ( $M=7.68, M=7.67)$. In all other motives, there were mean differences across different motives but the differences were not statistically significant $(p>0.05)$. The level of identification of Non-Indians was higher than Indian students ( $M=$ 7.06, $M=6.78$ ) but that was not found statistically significant.

Gender Differences. For exploring gender differences across sport motivations, data analysis was done in two stages. In the first stage, data analysis was done for the complete sample. Results revealed that two groups (Males \& Females) differed in context of two motives out of the five motive subscales (Table 2). Males scored significantly higher than females in both Eustress $(\mathrm{M}=7.30, \mathrm{M}=7.10)$ and Group Affiliation $(\mathrm{M}=7.74, \mathrm{M}=7.12)$ respectively. It was also found that males have more identification with sport $(M=7.01)$ than females (6.73) and the difference was also significant $(\mathrm{p}<0.05)$. For having a better understanding of gender differences, individual analysis was done for gender differences across Indians and Non-Indians samples. Results revealed that for Indians, significant gender differences exists across Group Affiliation ( $\mathrm{M}=7.86, \mathrm{M}=7.44)$, Eustress $(\mathrm{M}=7.90, \mathrm{M}=7.4)$, Aesthetics ( $\mathrm{M}=7.02, \mathrm{M}=$ 7.38) and identification with sport $(M=7.48, M=7.08)$ variables. In all these, males have higher motivation to watch sport when compared with females except Aesthetics value of sport. Similar analysis was done for exploring gender differences across NonIndians. Results revealed that significant differences exist between Group Affiliation (M $=7.74, \mathrm{M}=7.12)$, and Eustress $(\mathrm{M}=7.30, \mathrm{M}=7.10)$ motivations for Non-Indians respondents. In all the sport motivations, Non-Indian males score high motivation scores when compared with female Non-Indians. Results are as shown in Table 3.

\begin{tabular}{|l|l|l|l|l|}
\hline \multicolumn{5}{|c|}{ Table 3: Mean (Standard Deviation) of Motives Across Gender } \\
\hline \multirow{2}{*}{ MOTIVES } & INDIANS & NON-INDIANS \\
\cline { 2 - 5 } & MALE & FEMALE & MALE & FEMALE \\
\hline Group Affiliation & $7.86^{\mathrm{a}}(1.11)$ & $7.44^{\mathrm{a}}(1.06)$ & $7.74^{\mathrm{b}}(1.65)$ & $7.12^{\mathrm{b}}(1.45)$ \\
\hline Eustress & $7.90^{\mathrm{a}}(1.62)$ & $7.34^{\mathrm{a}}(1.77)$ & $7.30^{\mathrm{b}}(1.78)$ & $7.10^{\mathrm{b}}(1.49)$ \\
\hline Aesthetics & $7.02^{\mathrm{a}}(1.54)$ & $7.38^{\mathrm{a}}(1.60)$ & $7.09(1.56)$ & $7.00(1.87)$ \\
\hline $\begin{array}{l}\text { Self-Esteem (Vicarious } \\
\text { Achievement) }\end{array}$ & $6.41(1.77)$ & $6.89(1.99)$ & $7.23(1.86)$ & $7.02(1.90)$ \\
\hline Economic (Betting On Sport) & $3.77(1.98)$ & $4.18(1.78)$ & $4.54(2.12)$ & $4.01(2.10)$ \\
\hline Identification With Sport & $7.48^{\mathrm{a}}(1.56)$ & $7.08^{\mathrm{a}}(1.58)$ & $7.11(1.65)$ & $6.73(1.22)$ \\
\hline $\begin{array}{l}\text { Note: }{ }^{a} \text { Mean differences between Indian Male and Female significant at } P<0.05 . \\
\text { bMean differences between Non-Indian Male and Female significant at } P<0.05 .\end{array}$ \\
\hline
\end{tabular}

Source: Authors' own research 


\section{Discussion}

The success of many sporting events like IPL, ISL, HCL, PKL etc. in India, highlights the increasing importance and dominance of Indian sports market in the years to come. Therefore measuring fan motivation to watch sports is an important parameter to explore factors that motivate individuals to sport consumption. Previous researchers attempted to answer these questions taking different countries as context indicating that individual drives are different and people across the Globe have different motivations to watch sports (Won and Kitamura, 2007; Armstrong and Stratta, 2004). No such attempt was made so far, from an Indian perspective to explore various motivations of sport fans that drives them to watch sport. The current study explores different motivations for Indian youth to watch sports and to explore Nationality and Gender differences across those motivations.

It was found that youth differ from each other in terms of their motivations to watch sports which can help marketers to formulate strategies for their target segments (Kwon and Trail, 2001, Armstrong, 1998). Kwon and Trail (2001) found that Eustress $(\mathrm{M}=6.81)$ was the most important motivation for American students followed by Aesthetics ( $M=5.23)$, Self-Esteem ( $M=5.17)$, Group Affiliation ( $M=5.15)$ and Betting $(M=2.99)$. Findings of this study revealed that Indian youth differ in terms of their motivations. Their main motivation was Group Affiliation followed by Eustress and Aesthetics.

Group affiliation was found to be the most important motivation for youth to watch sports in general, indicating that youth use sports as a topic for discussion in groups with friends/relatives and are also affected by reference groups / friends when watching sports. Results showed that both Indian and Non-Indian students have statistically different Group Affiliation mean scores indicating that Group Affiliation is more important for Indians when compared with Non-Indians, though the difference is very less. Results showed that Group Affiliation was also found significantly different for Males and Females for the combined sample. Males have higher Group Affiliation motivations for both Indian and Non-Indian youth and gender does have a significant impact on this motivation irrespective of nationality.

Eustress (excitement factor) was the second important motivation of youth for watching sports. Nationality does not have a significant impact on Eustress motivation but Gender does have a significant impact on this motivation. For Indians as well as for Non-Indians, males have a high Eustress motivation for consumption of sport when compared with females. Both Indian as well as Non-Indians males are more excited about watching sport, in general, and enjoy competitive rivalry in sport in comparison to females. Aesthetics of a sport was found as the third most important motivation for youth. Both Nationality and Gender have a statistically significant impact on this motivation. Interestingly, this motivation is more important for Indian females who watch sport for its creative and artistic value.

Self -Esteem is also an important motivation for youth but data analysis revealed that both Nationality as well as Gender have similar levels of Self Esteem scores. It was also found that youth identifies more with sports. This finding was similar to Kwon and Trail (2001) who explained identification similarity using in-group favoritism theory as proposed by Lee (1985). However, the findings of this study show that Identification of sports is impacted by the Gender of the youth since level of identification of Male youths was found to be significantly more than Females. Betting as a motivation was found to 
MMCKS have least preference as a motivation to watch sports. This finding was similar to the findings of Kwon and Trail (2001).

For deeper understanding of the impact of Gender sport motivations, data was analyzed for individual nationality samples exploring interesting insights. Gender was found to have different impacts for different motivations based on individual's nationality. E.g. Group Affiliation and Eustress motives are considered important for both Indian and Non-Indian males when compared with females and the difference is significant for both. On the other hand Gender, do not have a significant impact on Aesthetics motivation for Non-Indians but has a significant impact for Indians. For Indian females, Aesthetic value of sport is an important motivation.

\section{Conclusion}

The present study provides a basic understanding of different sport motivations across youth from two distinct cultures and genders having implications for marketers involved in sports marketing by any means. Findings revealed that Group Affiliation was the most important motivation for youth to watch sports. Marketers can exploit the Group Affiliation dimension forming online groups or through virtual communities related to sports for their target customers in order to link with them. Marketers can exploit the Self Esteem dimension as an important motivation for youth by associating their brands with the favorite sport team of their target customers. Many marketers are already doing it in the form of sponsorship and sponsorship-linked marketing but the challenge is to identify which sport team their target customers like the most and feel more associated with.

Findings of the study can be used by marketers of sporting events in large private Universities to increase the footfall of spectators. Marketers of physical education departments of large international Universities can use the findings to promote sport events at a large scale by targeting relevant motivation of their target segments. Marketers need to understand existing cultural differences across their audiences, from different nations and gender, having an influence on their motivations to watch sports. This could help marketers to make relevant strategies to target their segments. For example, traditional Indian sporting events should be marketed differently based on the audience. For Males, Group Affiliation, Eustress and Self-Esteem motivational themes could be used for targeting them whereas the Aesthetic value of sport can be used to target Indian females so as to reach out to target audience in a friendly way. Similarly, Non-Indians will be more interested in art value provided by a particular sport and might rely more on replaying of audio as well as visual replays whereas Indians might be more interested in discussing with their friends / relatives who watch the same sports (Kwon and Trail, 2001).

\section{Directions for future research}

One of the limitations of the study is focusing primarily on exploring individuals' identification level towards sports in general. For this study, no particular sport was selected for measuring the identification as done by previous researches. This could affect an individual level of identification with particular sport because people identify differently with different sports. Previous researchers have taken a particular sport for respondents from both the nations and have explored cultural differences regarding a 
particular sport. Future researchers can further explore the identification of an individual with a particular sport in Indian context, for example Cricket or football etc., and can try to identify different motivations that drive an individual to watch that particular sport. Another limitation of the study is the focus on a particular age group, as such sports have no boundaries of age and people from different age groups have an urge and motivation to watch it. Future studies can be extended in the field to explore the impact of age group, by including broader age groups, on different motivations of individual's to watch sports.

Hsieh, Wang, and Yoder (2011) warned researchers to be careful while interpreting the findings of cultural differences researches beyond city levels. India is culturally a rich country where many sub-cultures exist within a particular region. There could be a possibility of different motivations towards watching sports across these subcultures also. Future studies could tap this research theme and could explore subcultural differences across sport watching motivations in different Indian states. Also, exploring nationality differences across sports watching motivations was one of the objectives of the study. To meet this objective data was collected from both Indian and Non-Indian youth using relevant sampling technique and a relevant sample size. NonIndian students came from different countries, having different cultures, and did not represent any specific country. Future studies can extend the same objective taking limited number of countries and exploring the nationality differences. Such studies can add meaningful insights to the literature.

\section{References}

Agas, K., Georgakarakou, C., Mylonakis, J., and Panagiotis, A. (2012),"Traveling Abroad internal and external motives toward different sports fan types”, International Journal of Business and Management, Vol. 7, No. 3, pp. 111-126.

Armstrong, G. (1998), "Football Hooligans: Knowing the Score", Oxford: Berg, Vol. 2, No. 3, pp. 344-347.

Armstrong, K.L., Stratta, T.M.P. (2004), "Market analyses of race and sport consumption", Sport Marketing Quarterly, Vol. 13, No. 1, pp. 7-16.

Bauer, H.H., Sauer, E.N., Schmitt, P. (2005), "Customer-based brand equity in the team sport industry: Operationalization and impact on the economic success of sport teams", European Journal of Marketing, Vol. 39, No. 5/6, pp. 496 -513.

Burke, R.R. (2002), "Technology and the customer interface: What consumers want in the physical and virtual store", Journal of the Academy of Marketing Science, Vol. 30, No. 4, pp. 411-432.

Correia, A., Esteves, S. (2007), "An exploratory study of spectators' motivation in football. International", Journal of Management and Marketing, Vol. 2, No. 5/6, pp. 572-90.

Dobel, J.P. (2010), "The Difference between Fans, Spectators and Audiences", available at: http://pointofthegame.blogspot.com/2010/04/spectators-audiences-andfans.html (accessed April 5th, 2015).

Hsieh, L.W., Wang, C.H., and Yoder, T.W. (2011), "Factors Associated with Professional Baseball Consumption: A Cross-Cultural Comparison Study", International Journal of Business and Information, Vol. 6, No. 3, pp. 135-159. 
MMCKS Kim, S., Greenwell, T.C., Andrew, D.P.S., Lee, J., Mahony, D.F. (2008), "An analysis of spectator motives in an individual combat sport: A study of mixed martial arts", Sport Marketing Quarterly, Vol. 17, No. 2, pp. 109-19.

Koo, G.Y., and Hardin, R. (2008), "Difference in Interrelationship between Spectators' Motives and Behavioural Intention Based on Emotional Attachment", Sport Marketing Quarterly, Vol. 17, No. 2, pp. 30-43.

Kwon, H., Trail, G. (2001), "A comparison of American and international students", Sport Marketing Quarterly, Vol. 10, No. 3, pp. 147-55.

Menefee, W.C. (2009), "Globalization in professional sport: A comparison of Chinese and American basketball spectators", Doctoral dissertation, North Carolina State University. Retrieved on $10^{\text {th }}$ September 2015, from http://repository.lib.ncsu.edu/ir/bitstream/1840.16/4824/1/etd.pdf.

Milne, G.R., McDonald, M.A. (1999), "Sport Marketing: Managing the Exchange Process", Jones and Bartlett Publishers, Vol. 32, No. 1, pp. 259-262.

Naik, A.Y., Gupta, A. (2012), "Indian Premier League and Team Brand Building: Validating the Spectator-Based Brand Equity Model in context of Television viewers", Metamorphosis: A Journal of Management Research, Vol. 11, No. 1, pp. $115-118$.

Price Water House Coopers Report. (December, 2011), "Changing the game: Outlook for the global sports market to 2015", available at: http://www.pwc.com/en_GX/gx/hospitality-leisure/pdf/changing-the-gameoutlook-for-the-global-sports-market-to-2015.pdf (accessed March 16th, 2015), pp. 6-22.

Reim, S. (2013), "Impact of Individualism and Collectivism on Sport Spectator Motivation", Otago Management Graduate Review, Vol. 11, No. 1, pp. 71-88.

Robinson, M.J. Trail, G.T, (2005), "Relationships among spectator gender, motives, points of attachment and sport preference", Journal of Sport Management, Vol. 19, No. 1, pp. 58-80.

Rosca, V. (2011), "Improving Sport Brands' Reputation through Marketing Events", Management \& Marketing, Vol. 6, No. 4, pp. 605-626.

Sloan, L.R. (1989), "The Motives of Sports Fans", in Goldstein, J.H. (ed.), Sports, Games, and Play: Social and Psychological Viewpoints, Hillsdale, N.J.: Lawrence Erlbaum Associates, Vol. 2, No. 1, pp. 175-240.

Sloan, L.R., Bates, S., Davis, W., and Schweiger, P.K. (1987), "Sports Need for Achievement and Power Scale (SNAPS)", Presented at the 59th Annual Meeting Midwestern Psychological Association, Chicago, IL, pp. 215-22.

Trail, G.T., James, J.D. (2001), "The motivation scale for sport consumption: Assessment of the scale's psychometric properties", Journal of Sport Behavior, Vol. 24, No. 1, pp. 108-27.

Wann, D.L. (1995), "Preliminary validation of sport fan motivation scale", Journal of Sport and Social Issues, Vol. 19, No. 4, pp. 377-396.

Wann, D.L., Grieve, F.G., Zapalac, R.K., Pease, D.G. (2008), "Motivational profiles of sport fans of different sports", Sport Marketing Quarterly, Vol. 17, No. 1, pp. 6-19.

Won, J., and Kitamura, K. (2007), "Comparative analysis of sport consumer motivations between South Korea and Japan", Sport Marketing Quarterly, Vol. 16, No. 2, pp. 93-105. 